\title{
the Journal \\ of CONTEMPORARY DENTAL PRACTICE \\ \begin{tabular}{lrr} 
& al WWW. the jcdp. COm \\
\hline Volume 9 & Number 7 & November 1,2008
\end{tabular} \\ Eating Disorders \\ Part II: Clinical Strategies for Dental Treatment
}

\section{Ana Cecilia Corrêa Aranha, DDS, MSc, PhD; \\ Carlos de Paula Eduardo, DDS, MSc, PhD; \\ Táki Athanassios Cordás, MD, PhD}

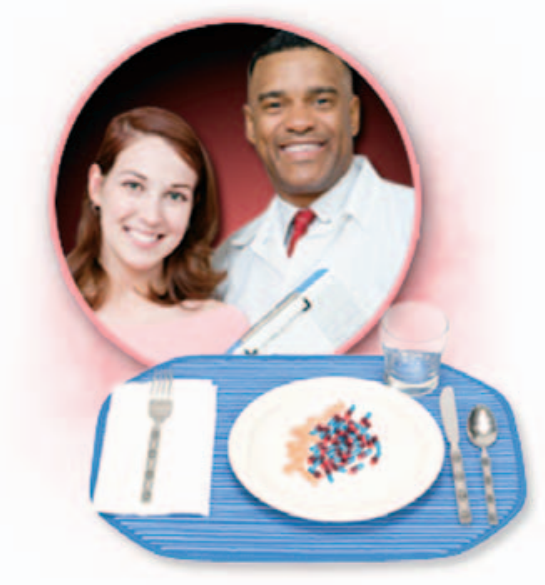

Aim: To present the strategies of treatment for dental implications of eating disorders.

Methods and Materials: A comprehensive review of the literature was conducted with special emphasis on the treatment of the oral implications of anorexia nervosa and bulimia nervosa, dividing the treatment into different parts.

Results: Oral manifestations of eating disorders represent a challenge to the dental pratitioner. Dental erosion, caries, xerostomia, enlargement of parotide glands, traumatized oral mucosa, and other oral manifestations may present in anorexic and bulimic patients.

Conclusion: Often the dentist is the first healthcare provider to observe the clinical symptoms of an eating disorder. Dental treatment should be carried out simultaneously with the medical treatment. However, dentists are not aware of the fundamental importance of the dentist's participation in the multidisciplinary treatment and no training is provided with regard to the strategies involved in the dental treatment.

Keywords: Oral complications of eating disorders are a major concern. The difficulties of recognizing the oral manifestations, and the failure to do so, may lead to serious systemic problems in addition to progressive and

○) Seer Publishing 
irreversible damage to the oral hard tissues. Considering the increasing incidence and prevalence rates of eating disorders, the dentist's participation and dental treatment should be discussed.

Keywords: Eating disorders, bulimia nervosa, anorexia nervosa, oral implications

Citation: Aranha ACC, Eduardo CP, Cordás TA. Eating Disorders Part II: Clinical Strategies for Dental Treatment. J Contemp Dent Pract 2008 November; (9)7:089-096.

\section{Introduction}

Eating disorders are classified as anorexia nervosa and bulimia nervosa. ${ }^{1}$ Both diseases are characterized by perturbed eating behavior patterns, a pathological control of body weight, and disturbance in the perception of the body shape. ${ }^{2}$ Due to their psychological and social harm, and the remarkable and significant levels of morbidity and mortality, they are cause for worry in modern society. ${ }^{2,3,4}$

For dental professionals, eating disorders are a serious concern and a clinical challenge. Eroded teeth, xerostomia, enlargement of parotide glands, and other oral manifestations may occur in eating disorder patients. ${ }^{5,6}$

A number of articles have been published correlating eating disorders with oral health, however, most of this research has been conducted by medical personnel and published in the medical literature. ${ }^{3,7,8}$ Nevertheless, dentists' participation in the treatment of eating disorders is fundamental because they could be the first healthcare providers to identify the clinical symptoms that suggest restrictive behavior and self-induced purging. ${ }^{3}$

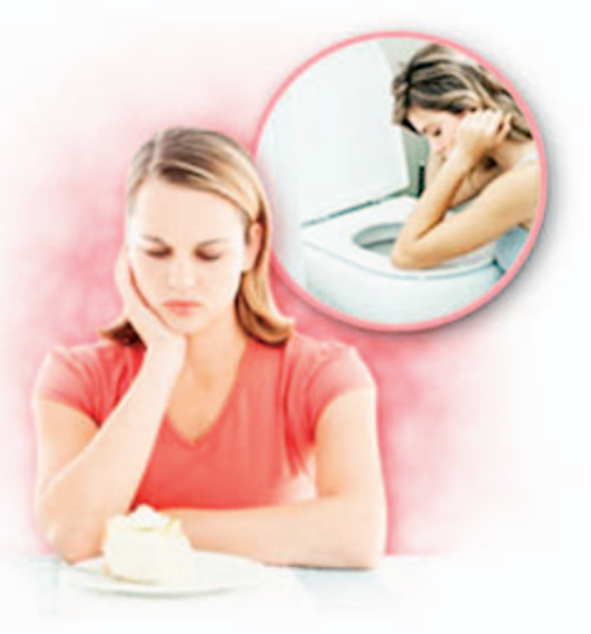

The dental team's awareness and knowledge of the signs, symptoms, and manifestations of eating disorders could lead to early detection and diagnosis. Subsequent referral of the patient for appropriate medical treatment will encourage a multidisciplinary therapeutic treatment approach that may have a successful outcome and a favorable prognosis.

Concurrent with the medical treatment, the dental treatment plan should promote oral heath and the recovery of masticatory and esthetic patterns. For dentists, diagnosing the oral consequences of eating disorders and providing treatment continue to be a clinical challenge as little information is available about treating patients with eating disorders. ${ }^{1,3,4}$ The difficulties of recognizing the oral effects of eating disorders, and failure to do so, may lead to serious systemic problems in addition to the progressive and irreversible damage to the hard tissues of the oral cavity. Thus, the main purpose of this review is to provide dentists and psychiatrists with information on the dental treatment of patients with eating disorders.

\section{Dental Treatment}

When a dentist perceives signs and characteristics of eating disorders, it is important to establish communication with the patient, in a non-threatening manner, to gather information to confirm a diagnosis. ${ }^{9}$

The medical history that most dentists use may not be adequate to diagnose the patient with an eating disorder. Additional questions that address duration and severity of the disorder, frequency of binging up or purging, periods of abstinence, factors precipitating binging up or purging, current status, and degree of control of aberrant behavior may be helpful for assessing the patient with an eating disorder. ${ }^{5}$ 


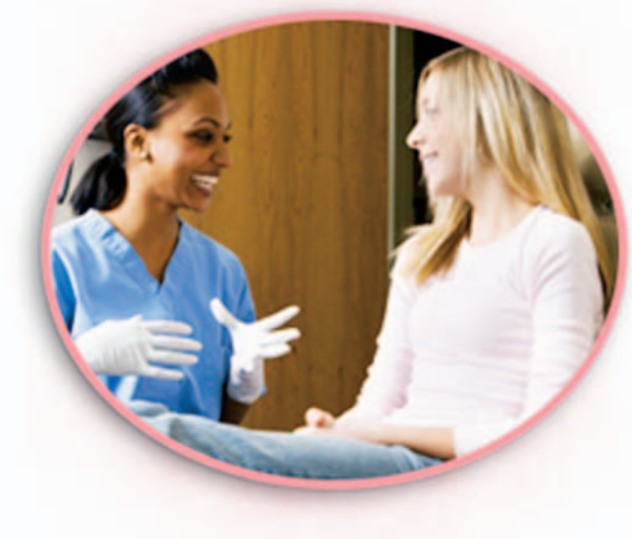

\section{Emergency Care}

Initially, the patient with an eating disorder may come to the dental office for treatment of an emergent condition. Most often complaints of thermal sensitivity caused by dentinal or pulpal exposure may prompt the patient to seek dental care.

The introduction of laser technology offers a contemporary alternative for the treatment of dentin recession. Experiments on the effects of laser have been related since 1964. Since then, it is now known that irradiating a tissue with low level laser therapy (LLLT) promotes an increase in protein synthesis by the cells as well as changes in the distribution of electrical charges in the cellular membrane.

The macroscopic effects observed are accelerated wound healing and analgesia. The irradiation should be absorbed to produce a physical and/ or chemical change that results in a biological response. Once the biological response is observed, the next step is to determine the optimal dose of radiation at a specific wavelength

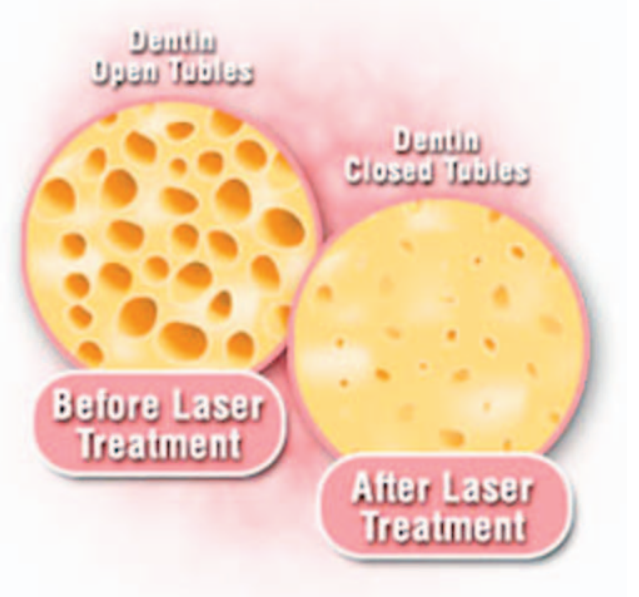

and the number of treatments to produce the necessary effect. ${ }^{10}$ Positive clinical results can be found in the literature concerning the use of low level laser therapy in the treatment of dentin hypersensitivity. ${ }^{11,12}$ In cervical recession with a maximum depth of $2 \mathrm{~mm}$ the use of low level laser therapy is indicated.

Apart from low level lasers, high intensity lasers (HILT) that have photo-thermal characteristics can also be used to treat dentin hypersensitivity. ${ }^{13}$ The Nd:YAG laser is preferred for this treatment due to its ability to melt the hydroxyapatite structure which, under cooling, re-solidifies forming hydroxyapatite crystal, larger than the initial structure. ${ }^{14}$ Scanning electron microscopy has shown a glazed surface with partial or total obliteration of dentinal tubules after therapy. ${ }^{15,16}$ Positive clinical results have been reported in the literature. ${ }^{17-20}$

If $\mathrm{Nd}: \mathrm{YAG}$ lasers are the preferred device for the treatment of dentin hypersensitivity, other laser equipment can also be used, such as the $\mathrm{CO}_{2}$ laser, Er:YAG, and recently the Er,Cr:YSGG laser. ${ }^{21-25}$ These lasers can also seal the dentinal tubules when used with energy below the ablation threshold. This means that low energies can produce modification of the dentinal structure and also acts as a low level laser.

It is necessary to consider the severity of the dentin hypersensitivity before a laser is used. However, considering its effective and simple mode of action, treatment with both low and high intensity lasers is the most conservative and appropriate option for the treatment of dentin hypersensitivity resulting from dental erosion.

In addition to lasers desensiting agents such as fluoride varnish, adhesive systems, potassium oxalates, and strontium chlorate can also be used. ${ }^{26}$

When treating patients with eating disorders, the dental team must also be aware of the clinical manifestations of hypoglycemia (venous blood glucose level below $50 \mathrm{mg} / 100 \mathrm{ml}){ }^{27}$ The stress resulting from the dental appointment concomitant with inadequate nourishment may precipitate palpitations, sweating, confusion, irritability, headache, seizure, and unconsciousness. Ready sources of carbohydrates such as orange juice, 
candy, and concentrated sports drinks should be available in the dental office emergency kit. ${ }^{28}$ If the patient experiences hypoglycemic syncope, even a small amount of frosting, if available, can be placed in the mucobucal fold area for rapid systemic glucose absorption. The dental treatment should be discontinued and the patient should be advised to eat a light meal or snack before the next dental appointment.

\section{Preventive Care}

Following emergency care, increased emphasis on preventive practices for the eating disorder patient should be one of the dental professional's goals. Preventive practices should begin immediately because the process of enamel erosion is irreversible and dental restorations will be required. The primary focus of the prevention program should be to prevent further destruction of tooth structure.

The initial phase of this program should be patient education. For patients who purge, a discussion of the causes and effects of perimylolysis is appropriate. Patients who are taking medications that have a xerostomic effect should be advised to use artificial saliva preparations that provide a lubricating effect on the tissues. Chewing sugar-free gum after meals may enhance remineralization and increase salivary flow for an anticaries effect. ${ }^{29}$ Diet and its role in caries formation should be presented to the patient as well as recommendations to decrease the intake of cariogenic and acidic foods.

A combination of regular professional examination, prophylaxis, in-office topical fluoride application, and a strict home-care regimen may prevent further dental deterioration.

The role of toothbrushing following selfinduced vomiting is unclear. Patients who brush immediately after vomiting may produce more wear than those who allow remineralization to occur after the acid attack. It is not known, however, whether the acid-eroded enamel is capable of being remineralized in the same way as the enamel caries subsurface zone is remineralized. ${ }^{27}$ There is a lack of consensus in the literature regarding extent of enamel erosion and its relationship to toothbrushing immediately after vomiting. However, there is

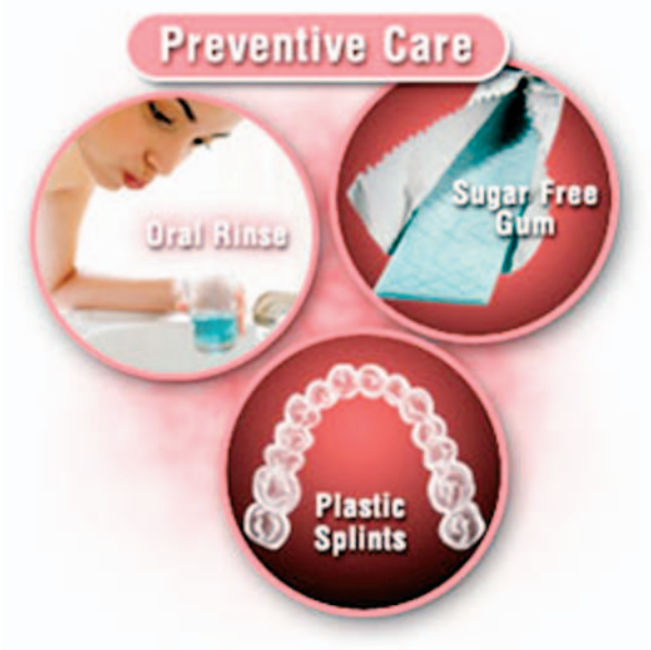

a recommendation to perform oral rinsing with $0.5 \%$ sodium fluoride, which is preferable to tooth brushing after self-induced vomiting to neutralize the acid that is regurgitated. Milosevic ${ }^{7}$ found the $\mathrm{pH}$ of vomitus ranges from 2.9 to 5.0 (mean $=3.8$ ), well below the critical $\mathrm{pH}$ for enamel remineralization.

Plastic splints designed for each patient may be an option to protect and buffer the teeth during the vomiting episodes. Some substances, such as sugar-free antacid, sodium bicarbonate in water slurry, or neutral sodium fluoride can be placed inside the splint before purging as an added defense against enamel dissolution.

The dentist's ability to provide and explain the variety of preventive care recommendations can positively influence in the medical treatment, in which case, the patient will have more control over his/her health by adhering to the prescribed regimen. Eating disorder patients are concerned about their physical appearance, so they may also be compulsive about maintaining good oral hygiene and seeking regular dental care.

\section{Restorative Treatment}

It is usually recommended to initate a temporary treatment plan to stabilize the existing damage, since a favorable prognosis for permanent treatment requires the end of the binge and purge episodes. Once the patient is psychologically stabilized, definitive restorative procedures can begin. ${ }^{30}$

On the other hand, to delay the definitive dental treatment until the eating disorder is under control may suggest the dentist has little confidence in the 


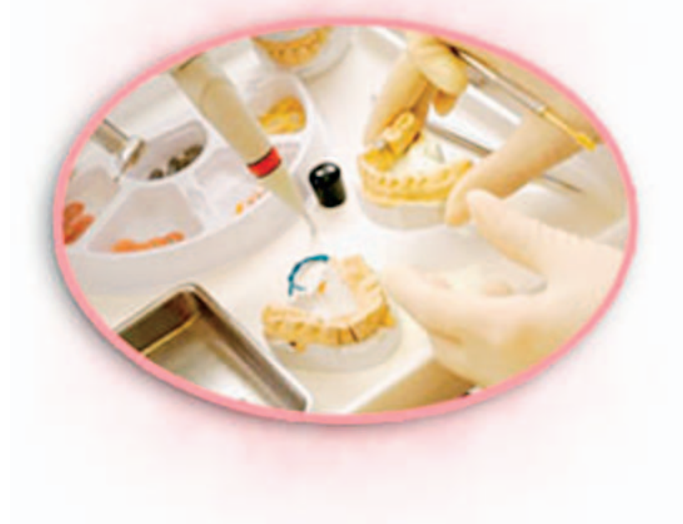

patient's ability to overcome the problem. ${ }^{1,31}$ The advantages to be gained versus the risks must be examined carefully. Monitoring the progression of these conditions may provide the dentist with an assessment tool that psychologists and psychiatrists do not necessarily have. The extent of the restorative treatment plan depends on the discomfort reported by the patient and the extent, severity, and depth of the lesions.

As described before, mild cases that do not involve great loss of hard tissue but present pain due to enamel removal and dentin exposure may require the application of desensitizer agents and laser irradiation as conservative treatment. In teeth that require restorations, composite resins or ionomer glass cements to reduce the hypersensitivity and prevent dental erosion may be preferable.

If the loss of dental enamel is severe in anterior teeth and compromises esthetics, porcelain veneers bonded with resin are required as they require less tooth preparation. ${ }^{32}$ In more severe cases when enamel erosion involving the posterior teeth has resulted in loss of vertical dimension, full-mouth reconstruction and occlusal rehabilitation are appropriate options. ${ }^{33}$ Complete coverage with crowns, veneers, or onlays to restore the dentition may be indicated. It should be emphasized that all rehabilitation should be conducted after the complete psychological recovery of the eating disorder patient.

In conclusion, the main objective of this review was to describe the dental implications of eating disorders in patients and also to suggest that a multidisciplinary approach is essential for lasting dental health in eating disorders patients. There is a need for appropriate training to better prepare oral health professionals for comprehensive care of the patient with eating disorders.

\section{Conclusion}

Early recognition of the oral manifestations of eating disorders can lead to favourable prognosis. Dentists that are aware of the signs and characteristics of eating disorders could be the first healthcare providers to detect, diagnose, and refer the patient for medical treatment resulting in comprehensive multidisciplinary approach to treatment. The dentist has the important role of screening patients for significant medical and behavioral disorders. Strategies should be discussed and clinically analysed in order to prepare the patient for the different stages of the dental treatment: emergency care, preventive care, and restorative treatment. 


\section{References}

1. De Moor RJG. Eating disorder-induced dental complication: a case report. J Oral Rehabil 2004; 31:725-732.

2. Little JW. Eating Disorders: Dental implications. Oral Surg Oral Med Oral Pathol Oral Radiol Endod 2002; 93;138-143.

3. Lask B, Bryant-Waugh R. Anorexia Nervosa and Related Eating Disorders in Childhood and adolescence. Psychology Press, 2nd edition, London, UK, 2001.

4. Frydrych AM, Davies GR, McDermott BM. Eating disorders and oral health: A review of the literature. Aust Dent J 2005; 50:6-15.

5. Studen-Pavlovich D, Elliott MA. Eating disorders in women's oral health. Dent Clin North A 2001; 45:491-511.

6. Abrams RA, Ruff JC. Oral signs and symptoms in the diagnosis of bulimia. J Am Dent Assoc 1986; 113:761-764.

7. Milosevic A, Brodie DA, Slade PD. Dental erosion, Oral Hygiene, and Nutrition in Eating Disorders. International Journal of Eating Disorders 1997; 21:195-9.

8. Nielsen S. Epidemiology and Mortality of Eating Disorders. Psychiatr Clin North Am 2001; 24:201-214.

9. Woodmansey KF. Recognition of bulimia nervosa in dental patients: Implications for dental care providers. Gen Dent 2000; 48:48-52.

10. Karu T. Laser biostimulation: a photobiological phenomenon. J Photochem Photobiol B 1989; 3:638-640.

11. Marsílio AL, Rodrigues JR, Borges AB. Effect of the clinical application of the GaAlAs laser in the treatment of dentine hypersensitivity. J Clin Laser Med Surg 2003; 21:291-6.

12. Ladalardo TC, Pinheiro A, Campos RA, Brugnera Júnior A, Zanin F, Albernaz PL, Weckx LL. Laser therapy in the treatment of dentine hypersensitivity. Braz Dent J 2004; 15:144-50.

13. Kimura Y, Wider-Smith $\mathrm{P}$, Yonaga K, Matsumoto K. Treatment of dentine hypersensitivity by lasers: a review. J Clin Periodontol 2000; 27:715-21.

14. Schaller HG, Weihing T, Strub JR. Permeability of dentine after Nd:YAG laser treatment: an in vitro study. J Oral Rehab1997; 24:274-281.

15. Lan WH, Lee BS, Liu HC, Lin CP. Morphologic study of Nd:YAG laser usage in treatment of dentinal hypersensitivity. J Endod 2004; 30:131-134.

16. Naylor FV, Aranha ACC, Eduardo CP, Arana-Chavez VE, Sobral MAP. Micromorphological analysis of dentinal structure after irradiation with Nd:YAG laser and immersion in acidic beverages. Photomed Laser Surg 2006; 24:755-763.

17. Renton-Harper P, Midda M. Nd:YAG laser treatment of dentinal hypersensitivity. Br Dent J 1992; 172:13-16.

18. Lier BB, Rosing CK, Aass AM, Gjermo P. Treatment of dentin hypersensitivity by Nd:YAG laser. J Clin Periodontol 2002; 29:501-506.

19. Ciaramicoli MT, Carvalho RC, Eduardo CP. Treatment of cervical dentin hypersensitivity using neodymium: Yttrium-aluminum-garnet laser. Clinical Evaluation. Laser Surg Med 2003; 33:358-362.

20. Lan WH, Liu HC. Treatment of dentin hypersensitivity by Nd:YAG Laser. J Clin Laser Med Surg 1996; 14:89-92.

21 Birang R, Poursamimi J, Gutknecht N, Lampert F, Mir M. Comparative evaluation of the effects of Nd:YAG and Er:YAG laser in dentin hypersensitivity treatment. Lasers Med Sci 2007; 22:21-4.

22. Aranha AC, Domingues FB, Franco VO, Gutknecht N, Eduardo CP. Effects of Er:YAG and Nd:YAG lasers on dentin permeability in root surfaces: a preliminary in vitro study. Photomed Laser Surg 2005; 23:504-8.

23. Schwarz F, Arweiler N, Georg T, Reich E. Desensitizing effects of an Er:YAG laser on hypersensitive dentine. J Clin Periodontol 2002; 29:211-5.

24. Moritz A, Schoop U, Goharkhay K, Aoid M, Reichenbach P, Lothaller MA, Wernisch J, Sperr W. Long-term effects of $\mathrm{CO} 2$ laser irradiation on treatment of hypersensitive dental necks: results of an in Vivo study. J Clin Laser Med Surg 1998; 16:211-5. 
25. Moritz A, Gutknecht N, Schoop U, Goharkhay K, Ebrahim D, Wernisch J, Sperr W. The advantage of CO2-treated dental necks, in comparison with a standard method: results of an in vivo study. J Clin Laser Med Surg 1996; 14:27-32.

26. Trowbridge H, Silver D. Review of current approaches to in-office management of tooth hypersensitivity. Dent Clin North Am 1990; 34:261-80.

27. Robb Nd, Smith BG. Anorexia e bulimia nervosa: Conditions of interest for the dental practitioner. J Dent 1996; 24:7-16.

28. Ranalli DN. Sports dentistry and mouth protection. In Pinkham JR (ed): Pediatric Dentistry: Infancy through Adolescence, ed 3. Philadelphia, WB Saunders, 1999, pp 635-644.

29. Leach AS, Lee GTR, Edgar WM. Remineralization of artificial-like lesions in human enamel in situ by chewing sorbitol gum. J Dent Res 1983; 68:1064-1068.

30. Hielsen KL. Treating dental patients with eating disorders. Dent Today 2006; 25:106-107.

31. Cowan RD, Sabates CR, Gross KBW, Elledge DA. Integrating dental and medical care for the chronic bulimia nervosa patient: A case report. Quintessence Int 1991; 22:553-557.

32. Hayashi M, Shimizu K, Takeshige F, Ebisu S. Restoration of erosion associated with gastroesophageal reflux caused by anorexia nervosa using ceramic laminate veneers: a case report. Oper Dent 2007; 32:306-310.

33. Kavoura V, Kourtis SG, Zoidis P, Andritsakis DP, Doukoudakis A. Full-mouth rehabilitation of a patient with bulimia nervosa. A case report. Quintessence Int 2005; 36:501-10.

\section{About the Authors}
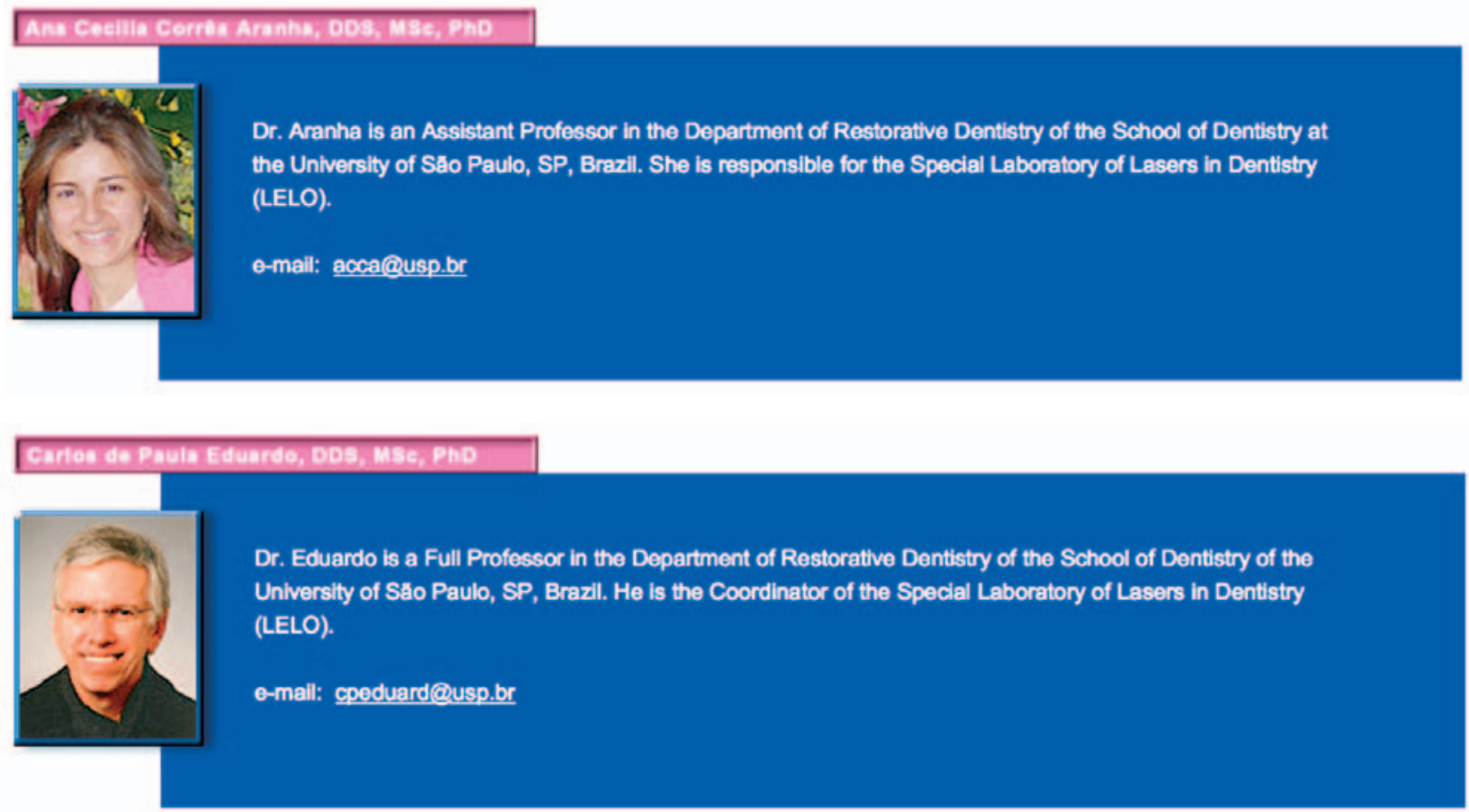


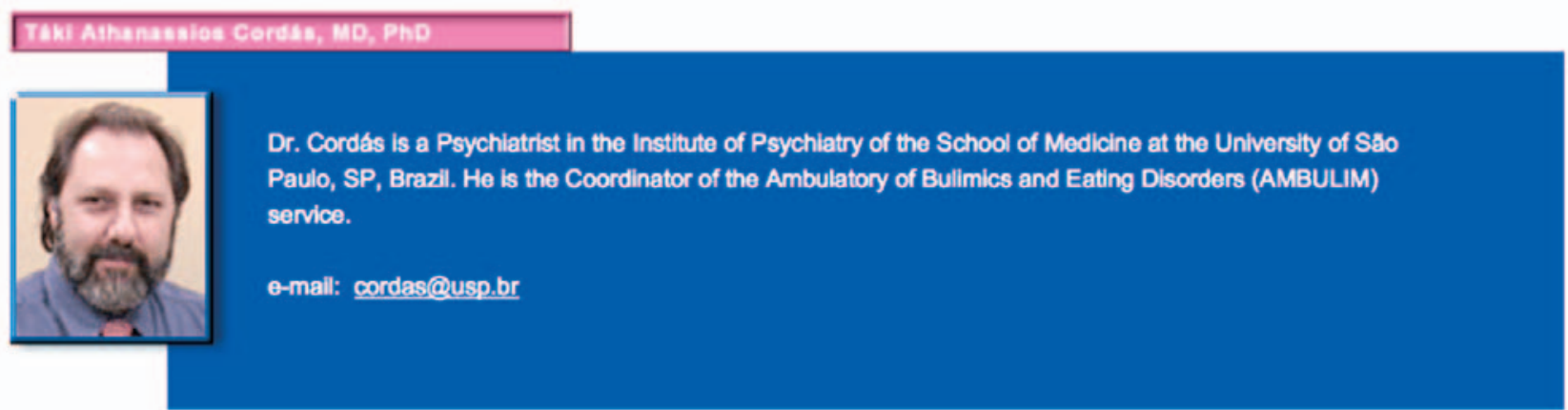

\section{Acknowledgements}

This work is a result of the partnership between the School of Medicine (Psychiatric Institute - AMBULIM Ambulatory Clinic for Bulimics and Eating Disorders) and the School of Dentistry of University of São Paulo (Department of Restorative Dentistry - Special Laboratory of Lasers in Dentistry/ LELO). 